\title{
Multi-carrier switching strategy for high-bandwidth potential balancing control of multilevel inverters
}

\author{
Zuraidi Md Tahir ${ }^{1}$, Auzani Jidin², Mohd Luqman Mohd Jamil ${ }^{3}$ \\ ${ }^{1-3}$ Faculty of Electrical Engineering, Universiti Teknikal Malaysia Melaka (UTeM), Malaysia \\ ${ }^{2}$ Power Electronics and Drives Research Group, CeRIA, UTeM, Malaysia \\ ${ }^{3}$ Electrical Machine Design, Power Electronics and Drives Research Group, CeRIA, UTeM, Malaysia
}

\section{Article Info \\ Article history: \\ Received May 11, 2021 \\ Revised Sep 8, 2021 \\ Accepted Sep 15, 2021 \\ Keywords: \\ CSF \\ Direct torque control \\ Induction motor \\ Neutral point clamp}

\begin{abstract}
This paper confers on investigation of a direct torque control (DTC) of induction motor drive by 3 level neutral point clamp (NPC) multilevel inverter. The imbalance problem may deteriorate the electric drive performances which might cause a short circuit condition. Various balancing control strategies were proposed, however, most of them employed complex space vector modulation (SVM) and hysteresis-based controller that generates variable switching frequencies. The proposed method will offer a reliable balancing control strategy with a constant switching frequency, and moreover, it will provide excellent electric drive performances. This research proposed a new multi carrier switching modulation strategy that establish a high-band-width control for neutral point potential in the NPC inverter. Potency of the proposed high-bandwidth potential balancing strategy is validated through the MATLAB/Simulink environment.
\end{abstract}

This is an open access article under the CC BY-SA license.

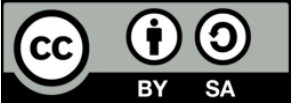

\section{Corresponding Author:}

Zuraidi Md Tahir

Faculty of Electrical Engineering

Universiti Teknikal Malaysia Melaka

Hang Tuah Jaya, 76100 Durian Tunggal, Melaka, Malaysia

Email: zuraidizmt@gmail.com

\section{INTRODUCTION}

In recent years, research on neutral-point-clamped (NPC) multilevel inverters has received significant interest due to its high-efficiency, low harmonic distortions and excellent drive performances, especially for medium-voltage, and high-power applications [1]-[5]. Because of simple structure and it allows a single direct current (DC) supply with lerger voltage values, the NPC inverter that introduced 33 years ago is the most widely used in many industrial applications. Although it also has an advantage, the inverter has a major drawback, namely imbalance capacitor voltages or neutral potential because of inappropriate ON-duration and selection of switching states [6]. The unbalanced voltages for the two DC-link capacitors significantly fluctuate the DC-link neutral point potential (NPP) which may cause failure of the switches due to over voltage stress. This problem may solve to some extent by increase the capacitance value but at the same time, the total cost of the system will increase [7]-[11]. Hysteresis-based controller [12] and space vector modulation (SVM) [13], [14] are available topologies to balance the voltages across DC-bus capacitor. The SVM approach also offers a constant switching frequency, reduction of current ripple and flexible implementation for vector control [13]. However, the SVM implantation to multilevel inverter involves complex control algorithm which may reduce the reliability of the control system. While the hysteresis-based controller provides robust balancing control, but it employs voltage sensors and produces variable switching frequency [15]. 


\section{SPACE VECTOR MODULATION}

Multilevel inverters based on standard two-level space vector pulse width modulation (SVPWM) feed by general SVPWM algorithm was proposed by applying two-level modulation to calculate the on-times and the reckoning of on-times for an n-level inverter become easier. The mapping vector are required to attain the proposed method of SVPWM for a multilevel inverter. This approach has gained popularity as several technical papers have reported to modify the two-level modulation in order to simplify the determination of number of triangular/sector, calculation of on-times and mapping of vectors [16]. Figure 1 shows an example in determining the switching of vectors using two-level based SVPWM in three-level NPC inverter as generally proposed in [17]. At first, the original reference voltage, $v^{*}$ needs to be modified to the new reference voltage vector, $v^{\text {new }}$ such that equivalent to that performed in two-level modulation. As it can be seen from the figure that the origin of $v^{\text {new }}$ is changed to locate at $\mathrm{v}_{\mathrm{Ll}}$, i.e. (221) or (110). Hence, the resultant vector $v^{\text {new }}$ is formed by the new direct- and quadrature-axis components, i.e. $v^{\text {new }}{ }_{\alpha o}$ and $v^{\text {new }}{ }_{\beta o}$, respectively. Therefore, the standard equation of on-durations of vectors calculated in two-level modulation can be used as given in (1).

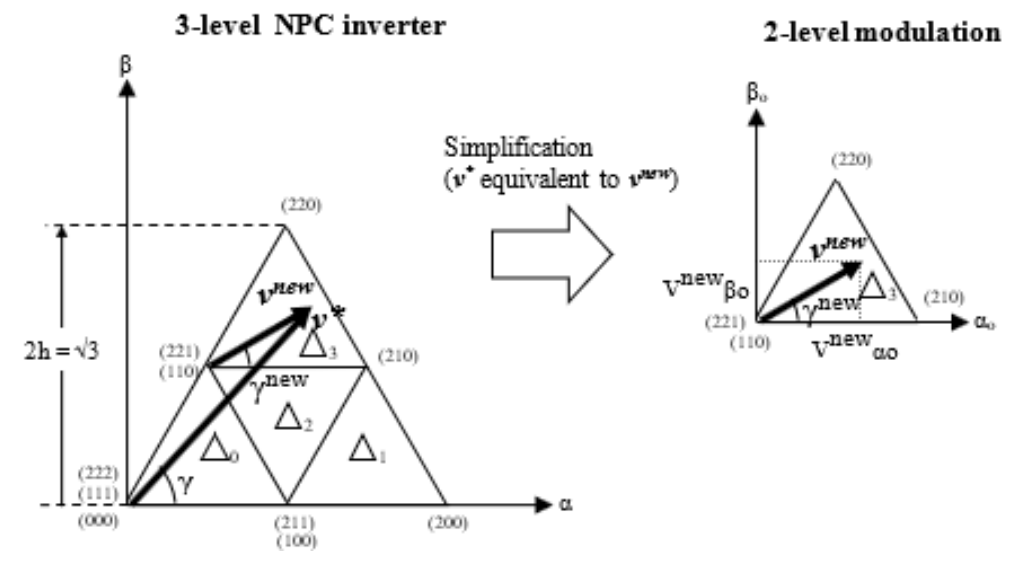

Figure 1. Redefine a new reference voltage vector that equivalents to two-level modulation

$$
\begin{aligned}
& t_{a}=T_{s}\left[v_{\alpha o}^{n e w}-\frac{v_{\beta o}^{n e w}}{2 h}\right] \\
& t_{b}=T_{s}\left[\frac{v_{\beta o}^{n e w}}{2 h}\right] \\
& t_{o}=T_{s}-t_{a}-t_{b}
\end{aligned}
$$

where $T_{s}$ is the switching period, $t_{a}$ and $t_{b}$ are the on-times for adjacent voltage vectors of $v^{\text {new }}$ within a triangular. Furthermore, before the mapping vectors conducted, it is desirable to determine the location of reference vector by defining the numbers of sector and triangular. Various techniques to define the sector and triangular have been proposed, in which aimed to reduce the algorithm complexity [17], [18].

In order to keep balance of neutral-point potential, the vectors at particular triangular/sector are switched in sequence as suggested by Hemanth and Makarand [19]. Considering a lower amplitude of reference vector (in $\Delta_{0}$ ), the suggested switching of vectors to keep the potential balancing is illustrated in Figure 2. It can be noticed that the switching of vectors within a sampling period avoid large different voltage resulted between the two capacitors, which consequently keep the balancing of neutral-point potential. Another approach introduced a virtual vector concept, i.e. without using the SVM technique [20]. However, the same idea of selecting the vector is employed where the vector is switch in sequence to compensate the imbalance potentials.

Ultimately, it can be found that the existing approaches may lead to two drawbacks, which are identified as switching of vectors in sequence does not guarantee the neutral-point potential to be balanced for long operations as uncertainty conditions, e.g. sudden large demand/load and dead-time effects may cause the two capacitors voltages deviate gradually. This will reduce the reliability of the system and second drawbacks are the switching of vectors in sequence is not optimized to enhance the power efficiency of

Multi-carrier switching strategy for high-bandwidth potential balancing control of ... (Zuraidi Md Tahir) 
inverter. By observing the order of switching in Figure 2, transition of vector $\mathrm{v}_{\mathrm{O}}(111)$ to $\mathrm{v}_{\mathrm{L} 1}(221)$ results in larger number of switching states for two phases of inverter. It should be noted that higher number of switching will increase the switching losses and hence reduce the efficiency, and this should be avoided for high power applications.

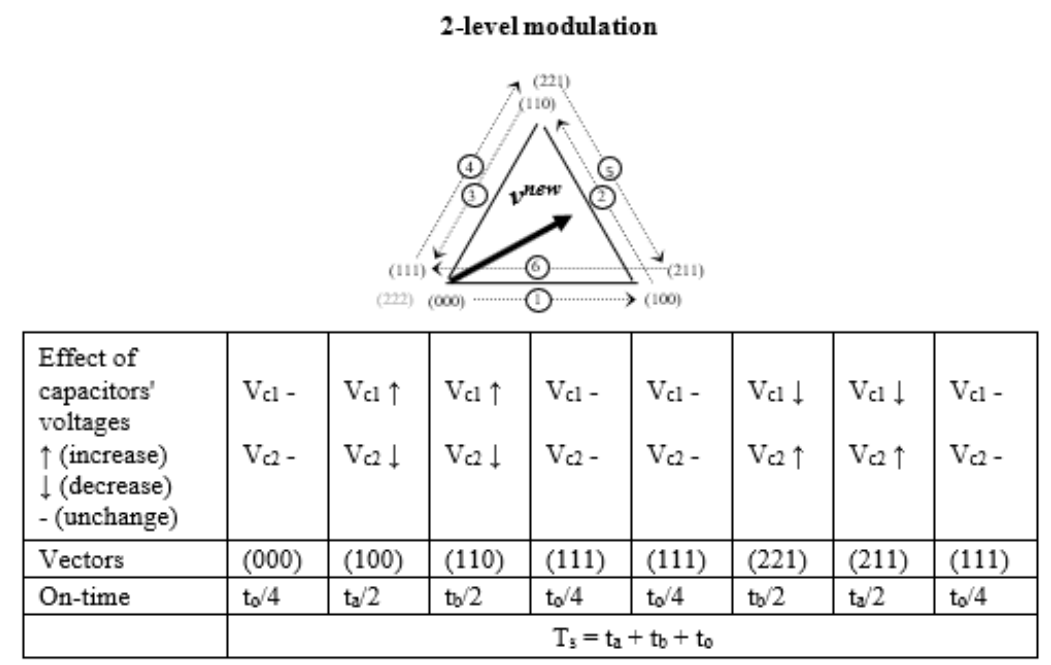

Figure 2. Switching vectors in sequence based on 2-level modulation for balancing strategy

\section{PROPOSED BALANCING CONTROL STRTATEGY}

Based on the investigation of effects on variation of capacitor voltages for every switching state possibility, appropriate ON duration and selection of switching state will be formulated using a look-up table and carrier based controller. The proposed control structure can be illustrated as shown in Figure 3 . The switching frequency of inverter will be determined by the carrier frequency [21]. It should be noted that the carrier frequency is set at a constant and high frequency to establish high control bandwidth. In so doing, the controller can be performed without the use of proportional integral (PI) controller, as utilized in [22].

As opposed to the SVM approach, the proposed method does not require estimator to calculate the reference $d$ - and $q$-axis reference space voltage vector which leads to complex control algorithms. The principle of balancing control strategy of the proposed method can be explained by Figure 4 . From this figure, the controllable quantities are compared to their reference to produce the errors which are then regulated by their respective carriers.

The controllable quantity that has quick response is compared to the carrier which has twice frequency than that of the controllable quantity that has lower response. It can be shown that the controllable that has lower response as well as smaller control bandwidth, its vector is directly changed due to the application of voltage vector, as given in (2).

$$
\Delta \bar{\varphi}_{s}=\left(\bar{v}_{s}-\beta\left(\bar{l}_{s}\right)\right) \cdot \Delta t
$$

where $\beta\left(\bar{l}_{s}\right)$ is the ohmic drop.

While, the controllable quantity that has quick response as well as high control bandwidth, its magnitude is directly affected by the $\Delta \bar{\varphi}_{s}$, as defined in (3), this yields.

$$
\delta_{e}=\bar{\varphi}_{s} \cdot k\left(\bar{l}_{s}\right) \cdot \sin \left(\theta_{\varphi}-\theta_{k r}\right)
$$

where $k$ is the first order function that has a low pass filtering action. By applying high carrier frequency and appropriate switching vectors, it is believed that the rate of change of $\delta_{e}$ does not exceed the absolute slope of carrier. It is therefore, the variation of capacitor voltages can be restricted around one half of DC voltage.

As it can be seen from the Figure 4, the errors of the controllable quantities are regulated within the carrier at high control bandwidth to establish appropriate selection of switching states and ON duration. It can be noticed that, the time taken to apply short amplitude of vector to increase (or decrease) the $\psi_{s}$ over one sampling period $\left(\mathrm{T}_{\mathrm{s}}\right.$ ) will be equally divided into two; one for selecting (211) (or (110)) and another one 
for selecting (100) (or (221)). In so doing, the voltage of both capacitors can be balanced without using voltage sensors, as employed in [12].

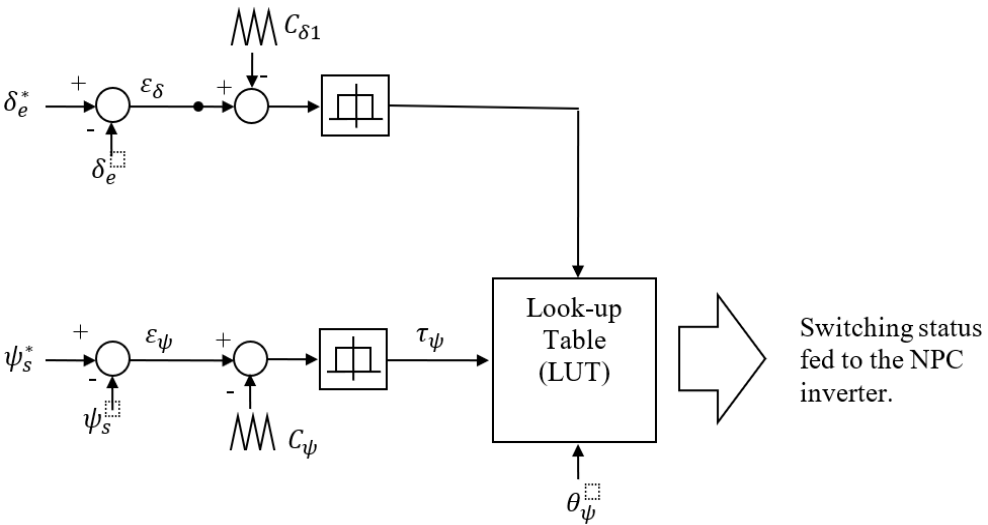

Figure 3. Control structure of the proposed method

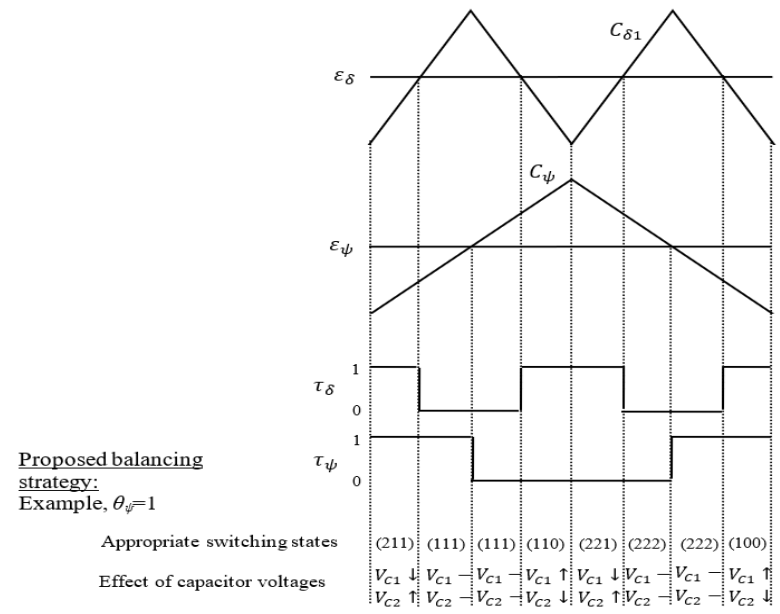

Figure 4. Proposed selection of switching state for balancing of capacitor voltages and constant switching frequency

\section{DIRECT TORQUE CONTROL OF INDUCTION MOTOR DRIVES}

Direct torque control (DTC) is a well-established technology for high power drive inverter introduce by Takahashi and Noguchi in 1896 [23] and this method is based directly on the torque (4) of the machine is being as [5]. Lot of technical paper have shown the great performance of DTC scheme using multilevel inverter [24]-[28]

$$
T_{e}=\frac{3}{2} p \frac{L_{m}}{L_{s} L_{r}-L_{m}^{2}}\left|\varphi_{s}\right| \cdot\left|\varphi_{r}\right| \sin \theta_{s r}
$$

Figure 5 show the structure of the direct torque control (DTC) for induction motor working with 3 level NPC inverter with multicarrier switching modulation strategy for high bandwidth potential balancing control. The system consists of an induction motor, 3-level NPC multilevel inverter, look-up table, voltage calculation, d-q current calculation sector detection, and proposed control structure. Three level NPC inverter as detail in Figure 6 was early introduced by Alias et al. in [25]. The inverver consists of a DC source, 12 switches IGBT, two capacitor and six diodes. Mapping of the voltage vectors produced by the three level NPC inverter shown in Figure 7. Based on their amplitude, the voltage vector can be categorized into four type of vector which are long, medium, short and zero voltage vector. Table 1 shows the type of vector, switching state and magnitude for each voltage vector type. 


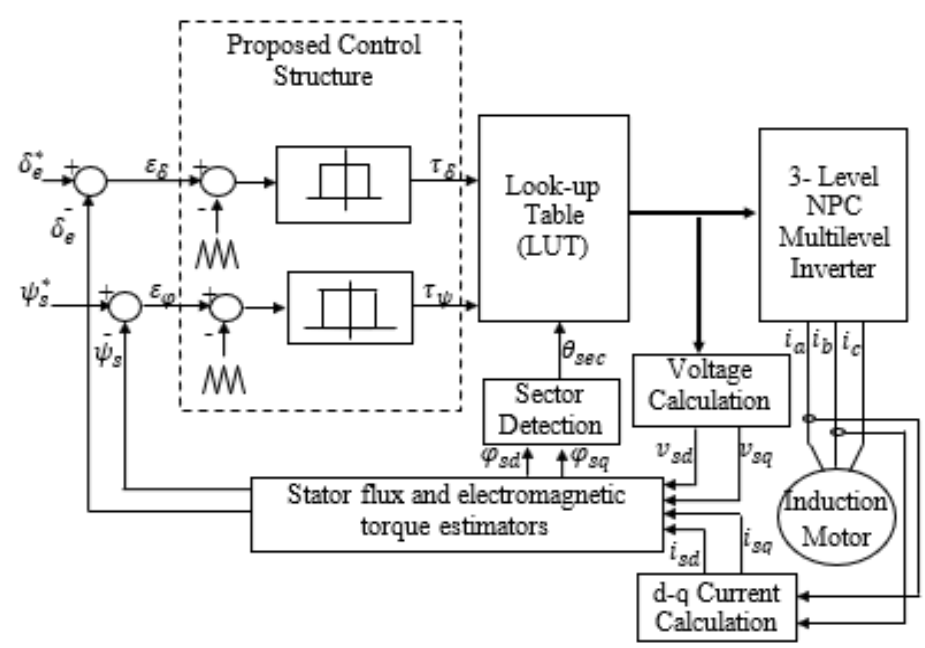

Fugure 5. DTC for induction motor working with 3 level NPC inverter with multicarrier switching modulation strategy

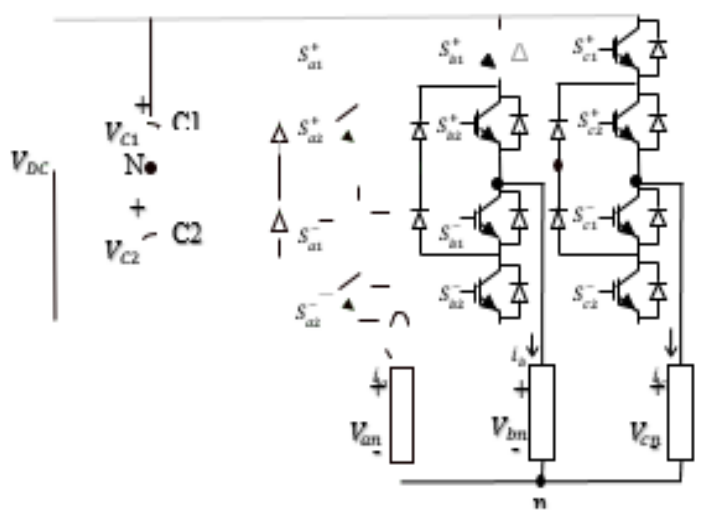

Figure 6. 3-level NPC multilevel inverter

Table 1. Type of voltage vetor ang magnitude of three-level NPC

\begin{tabular}{ccc}
\hline Type of voltage vector & Switching State & Magnitude \\
\hline Long amplitude & $220,200,202,002,022,020$ & $2 V_{d} / 3$ \\
Medium amplitude & $120,210,201,102,012,021$ & $V_{d} / \sqrt{3}$ \\
Short amplitude & $221,211,212,112,122,121,110,100,101,001,011,010$ & $V_{d} / 3$ \\
Zero amplitude & $222,111,000$ & 0 \\
\hline
\end{tabular}

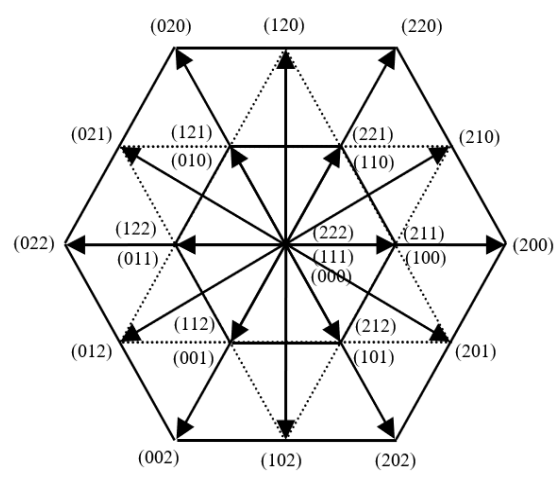

Figure 7. Voltage vector of Three level NPC inverter 


\section{SIMULATION RESULTS}

To investigate the effectiveness of the proposed method, the multi-carrier switching modulation strategy for 3-level NPC multilevel inverter has beed develop in MATLAB/Simulink enviroment. Table 2 show the parameter for the induction motor. In this experiment, the value of torque reference is set at 1.5 at initial condition, then rise to 2 after 1 second as shown in Figure 8.

From the simulation result, the proposed method shows the the estimated torque can follow the reference value while capacitor voltage VC1 and VC2 still regulate at half of Vdc at 120 vot. Figure 9 show carrier waveform compared to the torque error $\mathrm{T}_{\text {err }}$, it can be observing that the $\mathrm{T}_{\text {err }}$ regulate between the carrier so that the torque estimation regulates between the torque reference. In the Figure 10, current waveform $I_{a}$ show it increase corresponding to the increase of Toque while the flux stil remain regulate at the initial value as show in Figure 11.

Table 2. Induction motor parameters

\begin{tabular}{cc}
\hline Parameter & Value \\
\hline Stator resistance, $\mathrm{R}_{\mathrm{s}}$ & $6.1 \Omega$ \\
Rotor resistance, $\mathrm{R}_{\mathrm{r}}$ & $6.2298 \Omega$ \\
Stator self-inductance, $\mathrm{L}_{\mathrm{s}}$ & $0.47979 \mathrm{H}$ \\
Rotor self-inductance, $\mathrm{Lr}$ & $0.47979 \mathrm{H}$ \\
Mutual inductance, $\mathrm{L}_{\mathrm{m}}$ & $0.4634 \mathrm{H}$ \\
Number of pole pairs, $\mathrm{P}$ & 2 \\
DC Voltage & $240 \mathrm{~V}$ \\
\hline
\end{tabular}

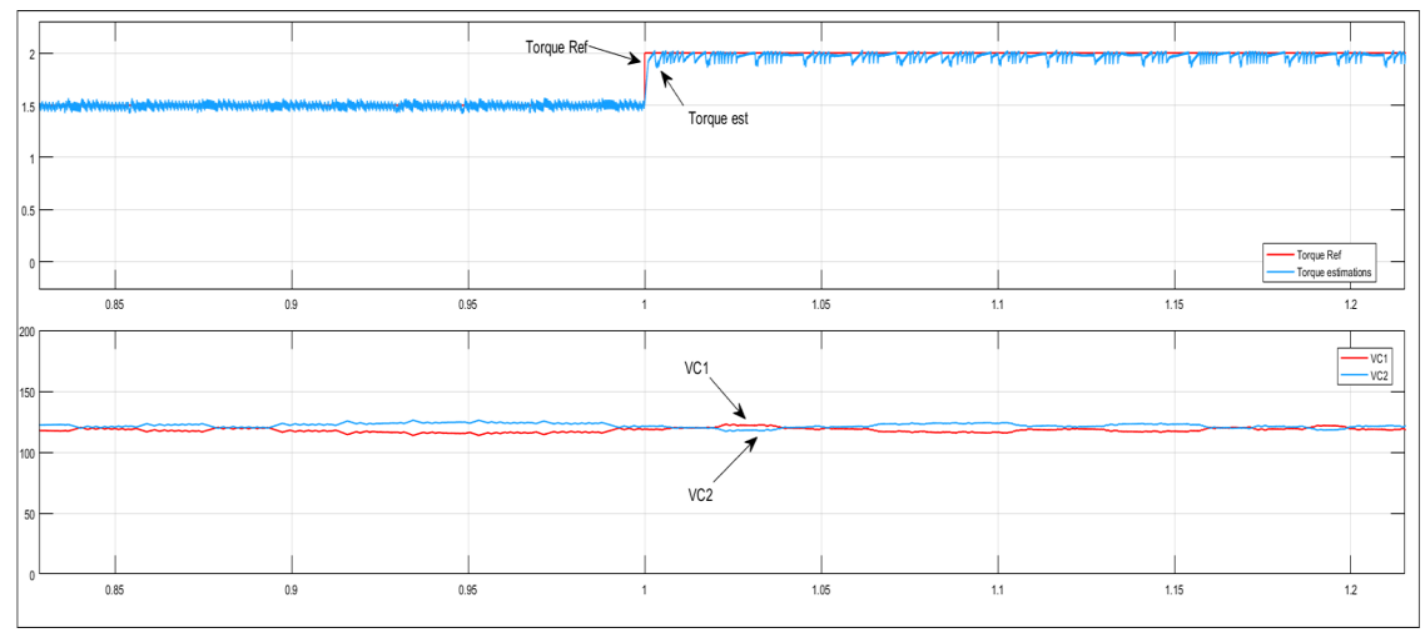

Figure 8. Torque response

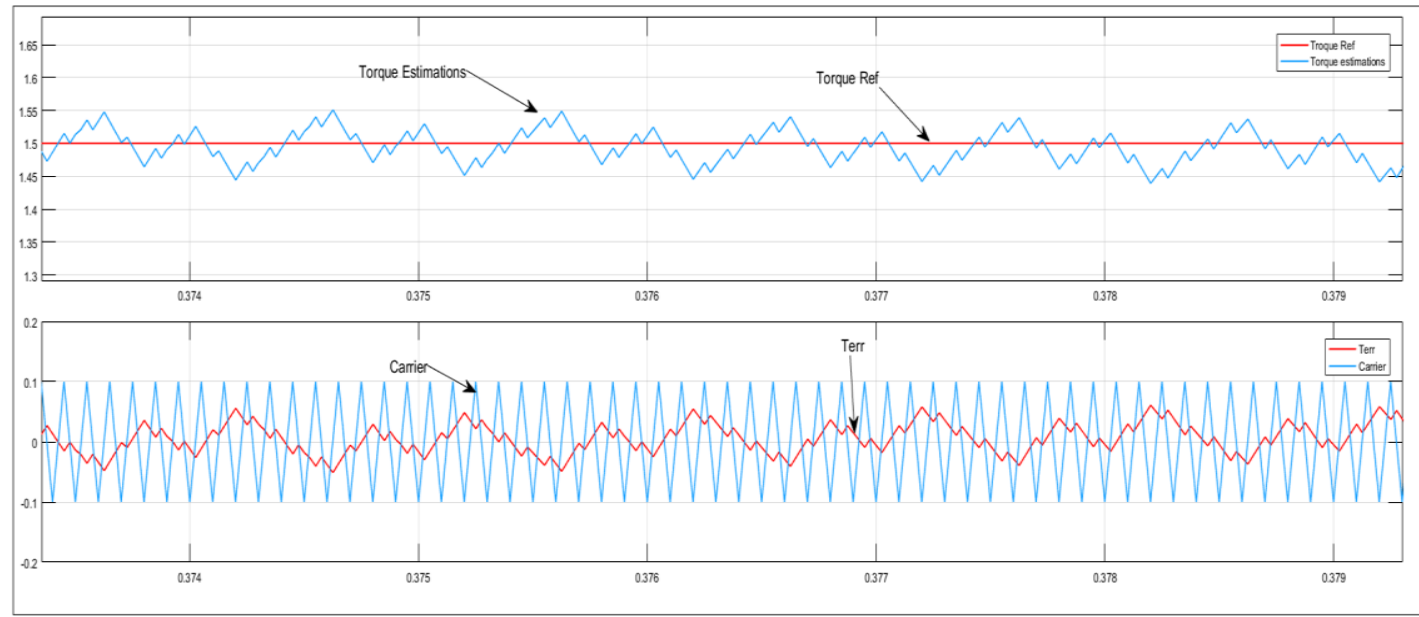

Figure 9. Carrier waveforms compare with torque error, Terr 


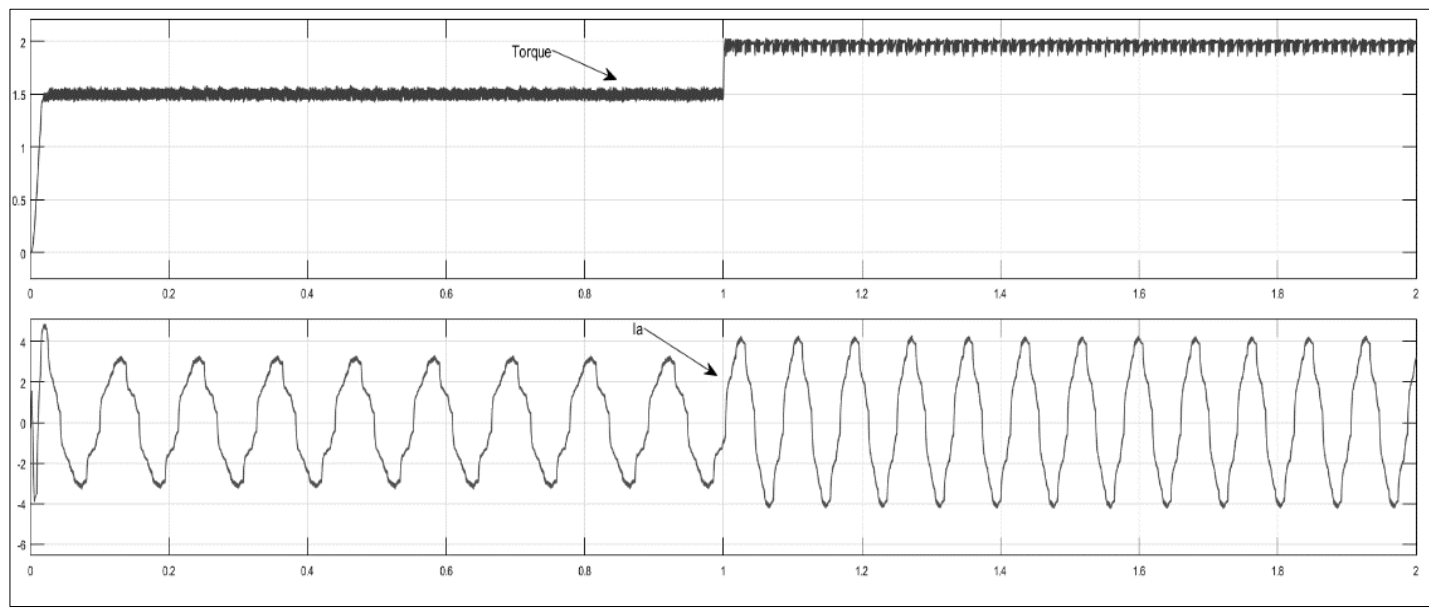

Figure 10. Torque estimator and current, Ia waveform

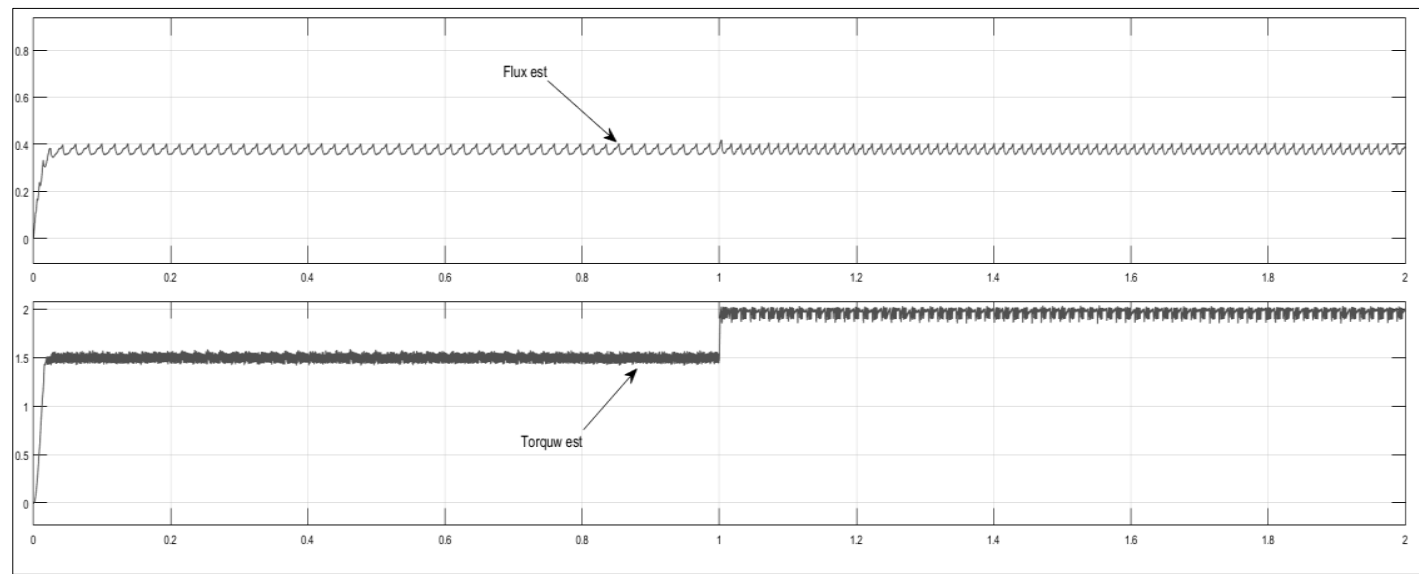

Figure 11. Flux and torque estimator waveform

\section{CONCLUSION}

In this paper, a simple control for induction motor performed by DTC fed by multi-carrier switching modulation to overcome the imbalance capacitor voltage problem of NPC. The proposed controlled strategy preserved the basic structure of the DTC and apply the multi-carrier switching modulation for switching frequency control and eliminate using the capacitor voltage sensor. MATLAB/Simulink result show, the proposed method is proved to overcome the capacitor imbalanced voltages. In steady state time, the capacitor voltage ripples are restricted to the acceptable value with torque in dynamic conditions.

\section{ACKNOWLEDGEMENTS}

The authors gratefully acknowledge the financial support provided by the Ministry of Higher Education, Malaysia (MOHE), and Universiti Teknikal Malaysia Melaka (UTeM).

\section{REFERENCES}

[1] C. Laoufi, Z. Sadoune, A. Abbou, and M. Akherraz, "New model of electric traction drive based sliding mode controller in field-oriented control of induction motor fed by multilevel inverter," International Journal of Power Electronics and Drive System (IJPEDS), vol. 11, no. 1, pp. 242-250, March 2020, doi: 10.11591/ijpeds.v11.i1.pp242-250.

[2] D. Roy, S. Kumar, and M. Singh, "A novel region selection approach of SVPWM for a three-level NPC inverter used in electric vehicle," International Journal of Power Electronics and Drive System (IJPEDS), vol. 10, no. 4, pp. 1705-1713, December 2019, doi: 10.11591/ijpeds.v10.i4.1705-1713. 
[3] G. Shashibhushan and S. Sonoli, "Multi-objective solution with PSO algorithm for minimization of torque ripple and speed settling time by using solar-fed 11,9 and 3-level multi-level inverter with vector control of induction motor," International Journal of Power Electronics and Drive System (IJPEDS), vol. 11, no. 2, pp. 827-832, June 2020, doi: 10.11591/ijpeds.v11.i2.pp827-832.

[4] G. Shashibhushan and S. Sonoli, "Starting torque and torque ripple reduction using SVPWM based vector control of induction motor with nine-level cascaded multilevel Inverter fed with solar PV power," International Journal of Power Electronics and Drive System (IJPEDS), vol. 10, no. 2, pp. 1123-1132, June 2019, doi: 10.11591/ijpeds.v10.i2.pp1123-1132.

[5] J. Rodriguez, S. Bernet, P. K. Steimer, and I. E. Lizama, "A Survey on Neutral-Point-Clamped Inverters," in IEEE Transactions on Industrial Electronics, vol. 57, no. 7, pp. 2219-2230, July 2010, doi: 10.1109/TIE.2009.2032430.

[6] B. Wu and M. Narimi, "High-Power Converters and Drive," 2nd Ed., New Jersey: John Wiley \& Sons Inc, 2017.

[7] D. Mohan, X. Zhang, and G. H. B. Foo, "A Simple Duty Cycle Control Strategy to Reduce Torque Ripples and Improve Low-Speed Performance of a Three-Level Inverter Fed DTC IPMSM Drive," in IEEE Transactions on Industrial Electronics, vol. 64, no. 4, pp. 2709-2721, April 2017, doi: 10.1109/TIE.2016.2636202.

[8] M. F. Escalante, J.-C. Vannier, and A. Arzande, "Flying capacitor multilevel inverters and DTC motor drive applications," in IEEE Transactions on Industrial Electronics, vol. 49, no. 4, pp. 809-815, Aug. 2002, doi: 10.1109/TIE.2002.801231.

[9] H. Ismail, et al., "Direct Torque Control of induction machine using 3-level neutral point clamped inverter," 2015 IEEE Student Conference on Research and Development (SCOReD), 2015, pp. 571-576, doi: 10.1109/SCORED.2015.7449401.

[10] A. Sadeghi, M. Mohamadian, M. Shahparasti, and A. Fatemi, "A new switching algorithm for voltage balancing of a three-level NPC in DTC drive of a three-phase IM," 2013 Twenty-Eighth Annual IEEE Applied Power Electronics Conference and Exposition (APEC), 2013, pp. 489-495, doi: 10.1109/APEC.2013.6520254.

[11] O. Sandre-Hernandez, J. Rangel-Magdaleno, R. Morales-Caporal, and E. Bonilla-Huerta, "HIL simulation of the DTC for a three-level inverter fed a PMSM with neutral-point balancing control based on FPGA," Electrical Engineering, vol. 100, no. 4, pp. 1441-1454, 2018, doi: 10.1007/s00202-017-0597-0.

[12] N. F. Alias, et al., "A simple potential balancing strategy for neutral-point-clamped inverter fed direct torque control induction machines," 2015 IEEE 11th International Conference on Power Electronics and Drive Systems, 2015, pp. 1002-1006, doi: 10.1109/PEDS.2015.7203551

[13] C. Hari Krishna, J. Amarnath, and S. Kamakshaiah, "Simplified SVPWM algorithm for neutral point clamped 3level inverter fed DTC-IM drive," 2012 International Conference on Advances in Power Conversion and Energy Technologies (APCET), 2012, pp. 1-6, doi: 10.1109/APCET.2012.6302002.

[14] A. K. Gupta and A. M. Khambadkone, "A Space Vector PWM Scheme for Multilevel Inverters Based on TwoLevel Space Vector PWM," in IEEE Transactions on Industrial Electronics, vol. 53, no. 5, pp. 1631-1639, Oct. 2006, doi: 10.1109/TIE.2006.881989.

[15] S. A. A. Tarusan, A. Jidin, M. L. M. Jamil, K. A. Karim, and T. Sutikno," A review of direct torque control development in various multilevel inverter applications," International Journal of Power Electronics and Drive System (IJPEDS), vol. 11, no. 3, pp. 1675-1688, September 2020, doi: 10.11591/ijpeds.v11.i3.pp1675-1688.

[16] Y. Firouz, M. T. Bina, and B. Eskandari," Efficiency of three-level neutral-point clamped converters: analysis and experimental validation of power losses, thermal modelling and lifetime prediction," Power Electronics, IET, vol. 7, no. 1, pp. 209-219, 2014, doi: 10.1049/iet-pel.2012.0711.

[17] U. Choi, J. Lee, and K. Lee, "New Modulation Strategy to Balance the Neutral-Point Voltage for Three-Level Neutral-Clamped Inverter Systems," in IEEE Transactions on Energy Conversion, vol. 29, no. 1, pp. 91-100, March 2014, doi: 10.1109/TEC.2013.2293502.

[18] N. R. N. Idris and A. H. M. Yatim, "Reduced torque ripple and constant torque switching frequency strategy for direct torque control of induction machine," APEC 2000. Fifteenth Annual IEEE Applied Power Electronics Conference and Exposition (Cat. No.00CH37058), 2000, pp. 154-161 vol.1, doi: 10.1109/APEC.2000.826099.

[19] B. H. Kumar and M. M. Lokhande, "Investigation of Switching Sequences on a Generalized SVPWM Algorithm for Multilevel Inverters,' Journal of Circuits, Systems, and Computers, vol. 28, no. 2, P. 1950036, 2019, doi: $10.1142 / \mathrm{S} 0218126619500361$.

[20] S. Das and G. Narayanan, "Analytical Closed-Form Expressions for Harmonic Distortion Corresponding to Novel Switching Sequences for Neutral-Point-Clamped Inverters," in IEEE Transactions on Industrial Electronics, vol. 61, no. 9, pp. 4485-4497, Sept. 2014, doi: 10.1109/TIE.2013.2293708.

[21] H. Ismail, F. Patkar, A. Jidin, A. Z. Jidin, N. A. N. Azlan, and T. Sutikno," Constant Switching Frequency and Torque Ripple Minimization of DTC of Induction Motor Drives with Three-level NPC Inverter," International Journal of Power Electronics and Drive System (IJPEDS), vol. 8, no. 3, pp. 1035-1049, September 2017, doi: 10.11591/ijpeds.v8i3.pp1035-1049.

[22] N. F. Alias, A. Jidin, A. Razi, T. Sutikno, and H. Ismail, "Simple Switching Strategy for High-Torque Control Performance utilizing Neutral Point Clamped Multilevel Inverter," International Journal of Power Electronics and Drive Systems (IJPEDS), vol. 3, no. 4, pp. 400-408, December 2013, doi: 10.11591/ijpeds.v3i4.5248.

[23] I. Takahashi and T. Noguchi, "A New Quick-Response and High-Efficiency Control Strategy of an Induction Motor," in IEEE Transactions on Industry Applications, vol. IA-22, no. 5, pp. 820-827, Sept. 1986, doi: 10.1109/TIA.1986.4504799.

[24] D. Islam, C. M. F. S. Reza, and S. Mekhilef, "DTC-IM drive with 5-level hybrid cascaded h-bridge inverter," 2014 9th IEEE Conference on Industrial Electronics and Applications, 2014, pp. 332-337, doi: 10.1109/ICIEA.2014.6931183. 
[25] N. F. Alias, A. Jidin, M. A. Said, A. R. Abdullah, H. Jopri, and N. H. Rahim, "Improved performance of Direct Torque Control of Induction Machine with 3-level Neutral Point Clamped multilevel inverter," 2013 International Conference on Electrical Machines and Systems (ICEMS), 2013, pp. 2110-2114, doi: 10.1109/ICEMS.2013.6713188.

[26] N. M. Nordin, N. A. Azli, N. R. N. Idris, N. H. Ramlan, and T. Sutikno," Constant Frequency Torque Controller for DTC with Multilevel Inverter of Induction Machines," International Journal of Power Electronics and Drive System (IJPEDS), vol. 7, no. 1, pp. 28-44, March 2016, doi: 10.11591/ijpeds.v7.i1.pp28-44.

[27] N. M. Nordin, N. R. N. Idris, N. A. Azli, and M. Z. Puteh, "Fuzzy-PI Torque and Flux Controllers for DTC with Multilevel Inverter of Induction Machines," International Journal of Power Electronics and Drive Systems (IJPEDS), vol. 5, no. 2, pp. 268-282, October 2014, doi: 10.11591/ijpeds.v5i2.6581.

[28] Y. Zhang, J. Zhu, Z. Zhao, W. Xu, and D. G. Dorrell, "An Improved Direct Torque Control for Three-Level Inverter-Fed Induction Motor Sensorless Drive," in IEEE Transactions on Power Electronics, vol. 27, no. 3, pp. 1502-1513, March 2012, doi: 10.1109/TPEL.2010.2043543.

\section{BIOGRAPHIES OF AUTHORS}

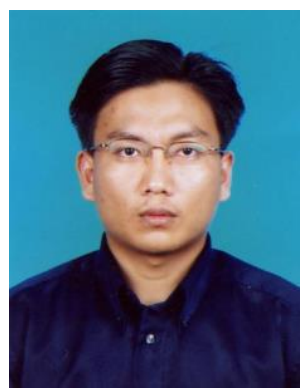

Z. M. Tahir received the B.Eng. degrees from Universiti Teknologi Malaysia, Johor Bahru, Malaysia, in 2002 and M.Eng. degrees from Universiti Tun Hussien Onn, Malaysia, in 2013. $\mathrm{He}$ is currently pursuing Ph.D. under Power Electronics and Drives Research Group (PEDG) in the Faculty of Electrical Engineering, Universiti Teknikal Malaysia Melaka, Melaka, Malaysia. His research interests include Power Electronics and Motor Drive Systems.

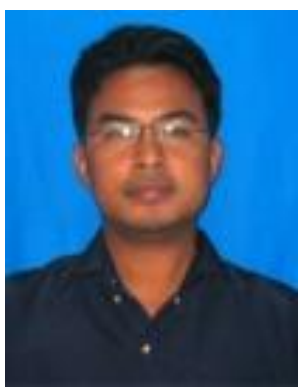

A. Jidin received the B.Eng. degrees, M.Eng. degrees and Ph.D. degree in Power Electronics and Drives from Universiti Teknologi Malaysia, Johor Bahru, Malaysia, in 2002, 2004, and 2011, respectively. He is currently an academician in Faculty of Electrical Engineering, Universiti Teknikal Malaysia Melaka, Melaka, Malaysia. He is also an active researcher in Power Electronics and Drives Research Group (PEDG) that established under the same faculty. His research interests include Power Electronics, Motor Drive Systems, Field-Programmable Gate Array, and DSP Applications.

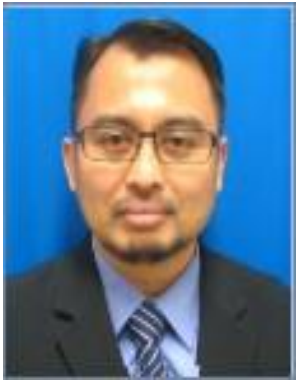

M. L. M. Jamil received B.Eng. degree from the Universiti Teknologi MARA, Shah Alam, Malaysia, in 2000, M.Sc. degree from University of Newcastle upon Tyne, U.K., in 2003, and Ph.D. degree from The University of Sheffield, Sheffield, U.K., in 2011, all in Electrical Engineering. He is currently an academician in Faculty of Electrical Engineering, University Teknikal Malaysia Melaka, Melaka, Malaysia. He is also an active researcher in Power Electronics and Drives Research Group (PEDG) that established under the same faculty. His research interests include the Design, Control, and Analysis of Permanent-Magnet Machines. 